\section{RICYDE. Revista Internacional de Ciencias del Deporte} doi: $10.5232 /$ ricyde

Rev. int. cienc. deporte

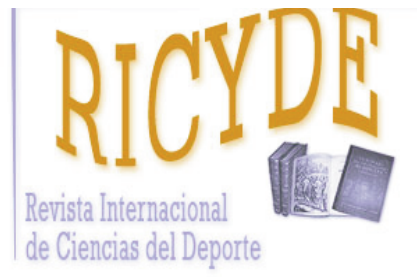

RICYDE. Revista Internacional de Ciencias del Deporte VOLUMEN XII - AÑO XII

Páginas:423-442 ISSN:1885-3137

Número 46 - Octubre - 2016

\title{
Las primeras profesoras de gimnástica en España. Profesión liberal y coartada durante el siglo XIX \\ The first female gymnastics teachers in Spain. A private and banned practice in the 19th century
}

\author{
Xavier Torrebadella1, ${ }^{1}$ Cristina López-Villar ${ }^{2}$
}

1. Universidad Autónoma de Barcelona. España

2. Universidad de A Coruña. España

\section{Resumen}

El objetivo de este artículo es una aproximación a la realidad de la profesión de profesora de gimnasia en los inicios de la configuración de dicha profesión. Por causa del aparente vacío doctrinal existente sobre esta temática durante el periodo estudiado, las fuentes de información empleadas proceden principalmente de fuentes archivísticas y hemerográficas de la época. Igualmente se ha recurrido a estudios actuales con el fin de centrar una posición desde la historia social de las prácticas gimnástico-deportivas. Las conclusiones del trabajo muestran que las primeras profesoras de gimnasia, a pesar de contar en un momento puntual con formación oficial, fueron vetadas para acceder a los institutos o incluso a escuelas normales, quedando relegadas a centros de educación infantil y primaria o al ejercicio de la profesión de forma privada o en gimnasios familiares. La moralidad de la época y el rol asignado a las mujeres actuaron como condicionantes claros para que su orientación profesional se vinculase a la gimnasia higiénica en el sistema educativo o a clases de gimnasia femenina en instituciones privadas. A pesar de esto, existieron mujeres que transgredieron dichos roles y que, precisamente por ello, se estudian aquí también.

Key words: profesión, gimnasios, mujeres, gimnasia femenina, gimnasia higiénica, educación física.

\section{Abstract}

The aim of this article is to offer a glimpse of the reality of the practice of female gymnastics teachers in the beginnings of its inception as a professional practice. Due to the apparent lack of disciplinary work on the topic in the period that is the object of our study, the sources of information that we have used are mainly archival and periodical. Likewise, we have resorted to current studies aiming at a positioning of sports and gymnastic practices considering socio-historical arguments. The conclusions of the work show that the first female gymnastic teachers, despite having at some point some formal training, were banned from accessing secondary schools, or even regular schools, being thus relegated to teaching in pre-elementary and elementary schools, or to teaching private lessons in family gyms. The morality of the time and the role assigned to women, clearly affected the way in which female teachers' professional careers were linked to hygienic gymnastic within the official school system, or to female physical education lessons in private institutions. In spite of this, there were women who transgressed those roles and who are therefore object of our current work.

Plabras clave: profession, gyms, women, female gymnastic, hygienic gymnastic, physical education. 
Torrebadella, X. y López-Villar, C. (2016). Las primeras profesoras de gimnástica en España. Profesión liberal y coartada durante el siglo XIX. RICYDE. Revista internacional de ciencias del deporte. 46(12), 423-442. http://dx.doi.org/10.5232/ricyde2016.04606

\section{Introducción}

Qalvo en el estudio de la época de la dictadura española, en la que se han realizado diferentes trabajos que permiten aproximarse a la profesión de profesora de gimnasia (Carbajosa, 1999; Manrique, 2010; Zagalaz, 2001), ha recibido poca atención la génesis de la profesionalización femenina en las prácticas gimnásticas y deportivas. Sin embargo, existen importantes trabajos que constituyen la base preliminar para construir una historia social en torno a las prácticas profesionalizadas de la actividad física de las mujeres (Arada, 2005; Arbaiza, 2000, 2002; Ballarín, 2007, 2011; Cortada, 1999, 2000; Flecha, 1996; Nash, 1983, 1995).

Como ha puesto de relieve Pilar Ballarín, las maestras fueron un colectivo de mujeres que ocuparon por primera vez un espacio profesional definido previamente como masculino, lo que provoca que emerjan contradicciones entre el papel asignado y el experienciado (Ballarín, 1999).

Con el objetivo de contribuir a cubrir parte del vacío en los estudios españoles, se presenta una investigación inédita sobre el alcance del ejercicio profesional femenino en el ámbito de las actividades gimnástico-deportivas del siglo XIX. El objeto de este trabajo es estudiar las circunstancias sociales que permitieron que la mujer española ejerciese como profesora de gimnasia así como las barreras que fue encontrando.

El método ha partido de la heurística con la identificación del corpus documental más relevante de las fuentes primarias del siglo XIX (Torrebadella, 2011a, 2011b) y de una aproximación hermenéutica a través de una visión sociohistórica de género.

Además hemos buscado otras fuentes primarias inéditas en los principales fondos documentales digitalizados: hemeroteca digital de la Biblioteca Nacional de España [http://www.bne.es/es/Catalogos/HemerotecaDigital/], Arxiu de Revistes Catalanes Antigues [http://www.bnc.cat/digital/arca/], Biblioteca Digital Memoria de Madrid [http://www.memoriademadrid.es] y Biblioteca Virtual de la Prensa Histórica [http://prensahistorica.mcu.es/es/estaticos/contenido.cmd?pagina=estaticos/presentación].

Una revisión cualitativita de los textos permite construir un análisis descriptivo y fenomenológico del estado de la cuestión, que descubre un espacio profesional apenas tratado y las avanzadas opiniones de las primeras profesoras de gimnástica y de educación física que coadyuvaron a la emergencia del feminismo social en España.

\section{El lugar de las mujeres}

A lo largo de todo el siglo XIX aún seguían vigentes las dogmáticas tradiciones sobre las mujeres que concibieron Luis Vives en Institutione feminae christianae o Fray Luis de León en La perfecta casada, cuyas obras fijaron los dispositivos católicos en la instrucción doméstica de la mujer burguesa (Ballarín, 2011). Como prolongación de estas obras, La educación de las niñas del Arzobispo François Fenelón, publicada en 1687, fue la guía omnipresente de la educación femenina del siglo XIX y silenció la polémica disertación de Fray Benito J. Feijoo en Defensa de las Mujeres de 1726, que desmentía la inferioridad de la mujer (Fernández-Quintanilla, 1981).

Es a partir del sexenio revolucionario cuando se perfilan los primeros atisbos que marcaron la visibilidad de los problemas sociales que afectaban a las mujeres. Durante todo el siglo XIX, la figura de la mujer liberal y trabajadora tuvo muy poca visibilidad y estuvo rodeada de una animadversión masculina (Nash, 1983). La incorporación de la mujer al proceso productivo 
Torrebadella, X. y López-Villar, C. (2016). Las primeras profesoras de gimnástica en España. Profesión liberal y coartada durante el siglo XIX. RICYDE. Revista internacional de ciencias del deporte. 46(12), 423-442. http://dx.doi.org/10.5232/ricyde2016.04606

fue concebida bajo una actividad subordinada al trabajo masculino y, puede afirmarse que esta condición no tenía otra finalidad que la de neutralizar su capacidad de decisión. El aumento del trabajo femenino en las fábricas de las principales zonas industriales del país conllevó un importante y progresivo flujo migratorio a las grandes ciudades. Es a partir de entonces que podemos avistar a una mujer obrera que cohabita en el trabajo junto al hombre y que interviene en las rutinarias manufacturas industriales y en las faenas agrícolas. En este substrato se edifica la imagen burguesa sobre la corporalidad e identidad de la clase obrera, que se caracterizaba por la debilidad, la enfermedad, la suciedad, la podredumbre, la perversión o la criminalidad. La presencia de las mujeres en el trabajo es discursivamente juzgada de inoportuna e inmoral, al contravenir los designios de la divina providencia, que la ha confinado al cuidado de la familia y de los quehaceres domésticos y privados (Arbaiza, 2000). Al aspecto moral o ideológico había que sumar que la presencia de mujeres en las fábricas se veía como una competencia desleal, al cobrar menos que los hombres.

Durante el siglo XIX, el arquetipo femenino que defiende y difunde el pensamiento católico apuesta por una educación dirigida básicamente al desempeño de las funciones del hogar y de la maternidad. Se sobreentendía que la carrera de la mujer era el matrimonio y su labor como ángel del hogar se orientaba en exclusiva a la crianza de los hijos y al cuidado. A partir de 1868, se intenta implantar una estabilidad democrática, campo de cultivo fundamental para que desde ciertos sectores liberales, socialistas y progresistas irrumpan intentos para desarrollar actuaciones que acometan mejoras en la educación social en general, y en la cuestión de la mujer en particular. En este contexto, el pensamiento krausista mantiene un enfoque radical al defender la educación de las niñas de manera básica e integral, en la misma línea que la de los niños, con el horizonte de que ambos sexos puedan ejercer posteriormente las distintas profesiones y acceder a los diferentes cargos sociales (Tacoronte, 2012).

En este contexto generalizado de fragilidad social de la mujer, toda manifestación o actitud femenina, que transgrediera los convencionalismos burgueses y moralizantes de la época, atentaba contra el orden y las normas y era conceptuada en ocasiones de ingenua, en otras de irreverente, de socialmente atrevida o, inclusive, de baja condición social. Es, pues, en esta tesitura que debemos ubicar algunas de las expresiones profesionales de las mujeres en torno al ejercicio corporal y las actividades gimnásticas.

\section{La educación física}

Si la educación física de los hombres aún era algo discutido en el siglo XIX, en el caso de las mujeres la situación era mucho peor. Sólo en algunos colegios de prestigio se introducía el baile como parte de la formación, entendiendo que esta práctica era acorde con el ideal de mujer delicada de la época.

Además, la influencia de las teorías eugenésicas y darwinianas situaban a la educación física de las mujeres como parte de la intervención médica que pretendía desarrollar dispositivos de feminización en la vida privada, doméstica y laboral, con el objeto de garantizar una higiénica maternidad y la mejora de la raza (Arbaiza, 2000; Torrebadella, 2011a).

Ejemplos de estos discursos son, por ejemplo, los del Dr. Seraine, que sentenciaba a las niñas desde la primera infancia a las obediencias domésticas y a los ejercicios propios de su sexo:

En el interior de la casa, las madres no sólo deberán ocuparse de hacerlas coser, hacer media y bordar, sino también instruirlas en las faenas caseras, a fin de que ejercitándose poco a poco lleguen a ser más tarde madres hacendosas. (Seraine, 1876, 120-121) 
Torrebadella, X. y López-Villar, C. (2016). Las primeras profesoras de gimnástica en España. Profesión liberal y coartada durante el siglo XIX. RICYDE. Revista internacional de ciencias del deporte. 46(12), 423-442. http://dx.doi.org/10.5232/ricyde2016.04606

En esta misma línea, Joaquín Lladó $(1868,125)$ indicaba que "ni física ni moralmente no debe traspasar la mujer los límites que el Criador le ha señalado, pues de lo contrario se haría indigna de la misión que lleva en la tierra".

Otros discursos apostaban claramente por la defensa de la educación, aunque se cuidaban de no ser incluidos dentro de los discursos de la emancipación. Es el caso del Director de la Escuela de Institutrices de Barcelona - centro fundado en 1892 por la Sociedad Económica Barcelonesa de Amigos del País, que ofrecía formación técnica y especializada preparatoria para la carrera de Institutrices y el ingreso a las escuelas de magisterio femeninas-, en cuyas palabras se aprecia la defensa de la educación como alternativa a los discursos de la domesticidad:

No la educamos para sabionda, ni la excitamos a luchar por su mal llamada emancipación, porque no la creemos oradora de club, ni siquiera electora en los comicios; pero, tampoco la declaramos eterna esclava de la calceta, ni colma nuestras ilusiones una cultura intelectual, poco más o menos al nivel de la comadre de vecindad. (Orriols, 1895, 9)

En este contexto la educación física de las mujeres se preocupaba por su delicada constitución, su sedentarismo, vicios postulares o por posturas fatigosas de los trabajos domésticos o fabriles. Desde estos aspectos, diferentes autores argumentaban la necesidad de la práctica femenina de la educación física, aunque esta preocupación era menor, ya que no era una actividad extendida. La gimnasia solamente era prescriptiva para las escuelas de párvulos, pero aún, no se había oficializado la gimnástica ni para la primera ni segunda enseñanza.

Alcántara García, pedagogo y secretario de la Asociación para la Enseñanza de la Mujer (creada en 1869), creía en la necesidad de elevar la cultura profesional de las mujeres, por lo que denunciaba que a la sociedad del momento le costaba aceptar la educación física de las niñas, mientras aceptaba completamente la de los niños. Como efecto de ello se producía, según él, que la legislación aún no prescribiera la gimnástica para el sexo femenino en todas las escuelas a principios del siglo XX (García, 1908).

De esta misma desigualdad hablaba también Torres-Campos (1884, 6-7), próximo al krausismo, denunciando que si hubiera merecido "igual atención la educación de las mujeres que la de los hombres, se hubiera comenzado por establecer la gimnasia en las escuelas de niñas y señoritas".

Pero no sólo hombres, sino también mujeres, como Emilia Pardo Bazán o Concepción Arenal, entre muchas otras, defendían la educación física femenina, considerando un error grave inculcar a las mujeres que su misión única fuese la de esposa y madre.

Por lo tanto, podemos afirmar que las personas próximas al krausismo y a la institución libre de enseñanza, tuvieron un papel fundamental en la defensa tanto del acceso de las mujeres a las profesiones como a la educación física.

Por otro lado, los gimnasios o las sociedades gimnásticas eran espacios de presencia fundamentalmente masculina. A pesar de esto, algunas mujeres, sobre todo niñas y jóvenes, pudieron realizar prácticas físicas. En el Gimnasio de Eusebio Ferrer, en Barcelona, entre 1875 a 1882, la presencia femenina llegó a 31 mujeres, mientras la presencia de hombres fue de 226 (A. V., 1882). En el Gimnasio de los hermanos Chuts en Valencia, entre 1870 a 1882, el número total de asistencia de señoras fue de 54; en cambio, la presencia en los hombres fue de 404 (Revista de gimnasios, 1882a). Y en el prestigioso gimnasio madrileño de Emilio 
Torrebadella, X. y López-Villar, C. (2016). Las primeras profesoras de gimnástica en España. Profesión liberal y coartada durante el siglo XIX. RICYDE. Revista internacional de ciencias del deporte. 46(12), 423-442. http://dx.doi.org/10.5232/ricyde2016.04606

Castañón, la participación femenina desde 1877 a 1882 fue de 77 mujeres, y la de hombres de 338 (Revista de gimnasios, 1882b).

Aunque se observe, por los datos anteriores, que la presencia masculina era muy superior, es interesante destacar que las mujeres también acudían a este tipo de establecimientos.

\section{La necesidad de la práctica}

Algunos médicos orientaban a las mujeres al ejercicio con el objeto de buscar el restablecimiento terapéutico de dolencias o enfermedades. Se trataba de mujeres o niñas de posición acomodada, cuyos padres de familia no tenían reparos en pagar el alto coste de las clases. Casos excepcionales fueron aquellos en los que las mujeres asistieron al gimnasio con la convicción de buscar el divertimiento y la robustez, que eran los de las mujeres próximas a directores o profesores de gimnasios.

Hay que destacar que el precio de las clases para las mujeres era superior que para los hombres. En 1863, en el Gimnasio Español de Joaquín Ramis las sesiones para señoras se cobraban a cincuenta reales, mientras que las de caballeros a treinta y cinco reales. El popular gimnasiarca José Florencio Quadras cobraba, en 1866, treinta reales al mes a los hombres y sesenta reales a las mujeres (Dalmau, 1947). Sin embargo, las clases de niños y niñas, aunque fuesen separadas, se cobraban a igual precio. En academias de gimnasia como la del francés Mr. Daniel, el coste era de veinte reales.

Frente a la preocupación higienista que incitaba a algunas familias a considerar la gimnástica como una práctica adecuada para las niñas, surgían también discursos moralizadores que recomendaban a los padres de familia que no llevasen a sus hijas a un gimnasio que no estuviese dirigido por una mujer y, menos sin antes consultar a un médico (Lladó, 1868). La figura del médico era primordial para realizar la prescripción de ejercicio, por lo que la mayoría de los gimnasios anunciaban la presencia de algún facultativo.

El hecho de que se recomendasen mujeres como profesoras de mujeres suponía un impulso para que algunas se abriesen camino en esta profesión definida por varones. Los recelos de algunos padres para enviar a sus hijas a los gimnasios se relativizaban cuando la encargada de las clases era una mujer. En esta misma línea, también se valoraba positivamente el hecho de que existiesen espacios separados para la práctica o incluso puertas de acceso diferenciadas a las salas (Círculo Gimnástico Barcelonés, 1871).

Con todo, seguía habiendo recelos, que venían marcados por el tipo de gimnástica practicada. El hecho de que el origen de la gimnástica estuviese estrechamente vinculada al circo (Torrebadella, 2013a), provocaba prejuicios en algunas familias que no consideraban apropiado para una señorita de clase acomodada la práctica de ejercicios funambulescos. Así lo manifestaban diferentes profesores (Ferrer, 1882; López Gómez, 1882) y también profesoras, destacando en este sentido los siguientes argumentos:

La creencia vulgar que hace que se confunda la gimnasia higiénica con la acrobática, ha retraído a muchas jóvenes de recibir los beneficiosos resultados que produce un ejercicio muscular convenientemente dirigido; pero hoy, afortunadamente, la mujer, ilustrándose, va comprendiendo que el trabajo físico es necesario, dadas las condiciones de vida sedentaria de la corte, y prácticamente los resultados obtenidos van extendiendo el conocimiento de la necesidad de esta costumbre.

La gimnasia en Madrid viene a ser un complemento necesario para la vida de la mujer durante la pubertad, época en que la naturaleza reclama la actividad del movimiento, y a 
Torrebadella, X. y López-Villar, C. (2016). Las primeras profesoras de gimnástica en España. Profesión liberal y coartada durante el siglo XIX. RICYDE. Revista internacional de ciencias del deporte. 46(12), 423-442. http://dx.doi.org/10.5232/ricyde2016.04606

la que la sociedad equivocadamente impone el yugo de la quietud, arrastrándola a la anemia y al neurosismo, tan comunes en las jóvenes de esta corte. (Parada, 1882, 4-5)

Aunque algunas personas intentaban desvincularse del origen circense de la práctica de la gimnasia, lo cierto es que en algunos gimnasios se ofrecía este tipo de práctica. Un ejemplo lo constituyeron las alumnas del gimnasio de Juan Estrany en Barcelona, que la prensa recogía de la siguiente forma:

El entusiasmo, sin embargo, llegó á su colmo cuando las señoritas Ana ventura y hermanas Carbó, colocadas de pies sobre tres bolas, dos de estas de reducidas dimensiones, las hacían avanzar y retroceder a su albedrío con la mayor serenidad de espíritu y pasmosa agilidad de las extremidades inferiores: ejercicio que hicieron más notable é interesante el gracioso balanceo y vertiginosa rapidez con que las tres alumnas hacían girar con sus diminutos píes en todas direcciones, aquellos esféricos y oscilantes cuerpos. (Gimnasia, 1879, 2)

Diferentes profesionales, desde la medicina o educación, argumentaban que las jóvenes eran las que más precisaban la gimnasia y lo razonaban desde la necesidad de combatir enfermedades consideradas propias de mujeres. Un ejemplo de esto es lo que decía el doctor Panadés $(1877,198)$, que consideraba que mediante esta práctica "hallarían un calmante seguro de su excesiva susceptibilidad nerviosa, y uno de los mejores remedios contra la clorosis". También la profesora de gimnasia Jesusa de Granda, de la que hablaremos más adelante, utiliza este tipo de argumentos, recomendando la gimnasia a las mujeres españolas como medio para curar la anemia o el histerismo (Granda, 1893). En un momento en el que la preocupación por los problemas de salud era una constante social, que llegó incluso a impregnar ciertas prácticas escolares, se convertiría en un aliado para la defensa de la práctica física de las mujeres. Este tipo de argumentos era constante en distintas mujeres, muchas de ellas maestras, pero también en otras de diferentes profesiones como Concepción Arenal.

La ciencia médica y la pedagógica comenzaban a caminar al unísono, con el objetivo de prevenir las altas tasas de mortalidad (Moreno-Martínez y Viñao-Frago, 2000), lo que fomentaba que el higienismo, y por tanto, la gimnasia entrasen en la escuela. El Reglamento de 1839 del Colegio Nacional de Huérfanas de la Unión, fundado en 1835 por la Reina María Cristina en el Real Sitio de Aranjuez, introdujo la educación física con juegos y aparatos gimnásticos con el objetivo de proporcionar una saludable recreación y desarrollo físico de las educandas, aspecto que indicaba una nueva perspectiva de la educación de las niñas (Torrebadella, 2013b).

Esta nueva preocupación hacia la educación física femenina en el contexto escolar fue tomando cada vez mayor importancia. Desde autores de reconocido prestigio como Joaquín Lladó, Pedro de Alcántara, o José Esteban García-Fraguas, a numerosas maestras, como por ejemplo Adela Riquelme o Pilar Pascual, escribieron sobre el tema (Torrebadella, 2011a).

Para algunos como García-Fraguas, el Congreso Pedagógico de 1892 inició un trazo de signo diferencial a favor de la educación de la mujer, citando como principales portavoces del cambio de orientación a Pedro de Alcántara García, Ángel Pulido, Joaquim Sama, Concepción Arenal, Emilia Pardo o María Solo de Zaldivar (García-Fraguas, 1892). GarcíaFraguas $(1896,281)$, haciéndose eco de las conclusiones del citado Congreso, puso de relieve la necesidad de motivar a las mujeres para la educación física con el objetivo de conseguir "el renacimiento físico de la raza, esgrimiendo razones del orden estético o maternal, según convenga a los intereses sociales e históricos del pueblo español”. 
Torrebadella, X. y López-Villar, C. (2016). Las primeras profesoras de gimnástica en España. Profesión liberal y coartada durante el siglo XIX. RICYDE. Revista internacional de ciencias del deporte. 46(12), 423-442. http://dx.doi.org/10.5232/ricyde2016.04606

La ideología regeneracionista también contribuyó a los discursos a favor de la educación física de las mujeres, aunque existían diferentes líneas de pensamiento, que es algo que muestra la intervención de Carmen Rojo en el congreso anteriormente nombrado. Esta profesora, que dirigía la Escuela Normal de Maestras de Madrid, se oponía a la reivindicación gimnástica.

Dentro de los discursos que sí defendían dicha práctica, también se incluía la necesidad de diferenciar las prácticas de hombres y mujeres, incluso del tipo de implementos que se utilizaban. Mientras algunos recomendaban ciertos aparatos, otros se inclinaban únicamente por la gimnasia de sala (Arellano y Martínez, 1894; García-Fraguas, 1896; Mosso, 1894). Dichos argumentos siempre se apoyaban en aspectos relacionados con el ideal de belleza de la debilidad:

Más hay que tener en cuenta que no son los mismos ejercicios a que ambos sexos deben someterse. La gimnasia en la mujer ha de tender más al desarrollo, al equilibrio de las fuerzas, cuidando de conservar la natural suavidad y delicadeza femeninas. (Gimnasio Médico Eduardo Tolosa, 1897, 1)

La fuerza era una capacidad física que definía a los hombres frente a la debilidad, ya comentada, de las mujeres. Por lo tanto, se proponía un tipo de gimnasia diferente para hombres y mujeres, tal como se recoge en la siguiente cita: "La mujer es más débil y sería un absurdo el querer que tuviese formas hercúleas y mirara la gimnasia bajo el punto de vista de la fuerza" (Lladó, 1868, 126).

\section{Las primeras profesoras}

La entrada de las mujeres a la profesión de profesora de gimnasia debe analizarse desde diferentes prismas, ya que existieron varios elementos que contribuyeron a su presencia en la sociedad del momento. En primer lugar, hay que destacar los gimnasios decimonónicos, ya que algunos gimnasiarcas de la época recurrían a sus hijas o mujeres para que impartiesen clases, primero como ayudantas y posteriormente haciéndose cargo de las clases para el género femenino. Las primeras orientaciones de la gimnástica femenina en estos contextos sería próxima a las actividades de circo, para, progresivamente y ante una creciente demanda entre las clases acomodadas, transformarse en una gimnasia con fines higiénicos.

Otro elemento fundamental para la creación de la figura de profesora de gimnasia fue que las maestras, con mayor o menor conocimiento, incluían la educación física como un elemento importante en la formación de niños y niñas. Pero quizás el elemento de mayor implicación política fue la creación de la Escuela Central de Gimnasia en 1883, constituyéndose como el primer centro, en la historia de España, dedicado a formar profesionales de ambos géneros para este fin.

Algunas de las primeras referencias de mujeres ejerciendo de profesoras de gimnasia ya han sido recientemente presentadas por Torrebadella (2011a, 2013b, 2014), al considerar las aplicaciones de la gimnasia ortopédica a mediados del siglo XIX en Barcelona, así como al hablar de la vallisoletana Teresa Castellanos de Mesa, que la sitúa como la primera profesora de gimnástica (educación física) de España, al impartir ejercicios de calistenia a las niñas del Colegio de Loreto Francés en Madrid. Pero además, cita Torrebadella (2013b) que esta profesora dispuso de un gimnasio y una sala de esgrima en la Fonda de las Diligencias Peninsulares (un negocio por cuenta propia), dando origen a una de las primeras emancipaciones femeninas en el ejercicio de la profesión gimnasiarca; una posición muy atrevida para la época, socialmente independiente y liberal, cuando todavía no estaba casada. 
Torrebadella, X. y López-Villar, C. (2016). Las primeras profesoras de gimnástica en España. Profesión liberal y coartada durante el siglo XIX. RICYDE. Revista internacional de ciencias del deporte. 46(12), 423-442. http://dx.doi.org/10.5232/ricyde2016.04606

Torrebadella (2013b) cita otros ejemplos en la década de los años sesenta. Uno es en Barcelona, donde Francisca Vall, hermana del reputado gimnasiarca Manuel Vall, tras aprender el oficio abrió su propio establecimiento hacia 1861, exclusivo para señoritas. Otro ejemplo es el de Alfonso Vignolles, que a su llegada a Madrid hacia 1861, no solamente ofreció un impulso a la gimnástica higiénica como citaba Busqué (1865), sino que además posibilitó que su mujer (la Sra. Vignolles) se hiciera cargo de la gimnasia del Ateneo de Santa Isabel, un colegio de señoritas.

Así pues, nos encontramos con un modelo de mujeres, igual que en el caso anterior, muy diferente al modelo general que se imponía en la época.

En el campo educativo, Fernando de Castro y el grupo krausista de Sanz del Río iniciaban las primeras conquistas institucionales de las reivindicaciones de las mujeres como la Escuela de Institutrices y la Asociación para la Enseñanza de la Mujer, que permitieron que, a semejanza de estas, fuesen creadas otras en Valencia, Málaga, Barcelona, Palma de Mallorca, Vitoria, Granada, Sevilla o Bilbao (Scalon, 1986). Estos centros tuvieron un papel principal en la apertura de nuevas vías de trabajo para las mujeres y específicamente para el caso de la gimnasia. En 1882, la Escuela Normal de Maestras de Madrid introducía, de nuevo, pero esta vez como asignatura obligatoria, la denominada "gimnasia de sala" para los cuatro cursos (Sección oficial, 1882; Torrebadella, 2014a).

Esta asignatura se encontró con ciertas críticas, que en el caso del doctor Sardá se intentó disipar en un artículo dirigido a los padres, en el que defendía la gimnasia como parte de la higiene:

[...] la gimnasia que se manda enseñar en la Normal de Maestras, es la gimnasia de sala, que está tan lejos de los ejercicios de los volatineros, con los que, comparándola, han querido algunos ridiculizar la nueva asignatura, como lo están, el paseo, el baile, la esgrima, los ejercicios vocales y otros de la misma naturaleza. (Sardá, 1882, 225)

Volvemos a encontrarnos aquí las sospechas sobre esta materia, Concepción Sáiz de Otero argumentaba que debido a las malas condiciones en que se verificaba la Gimnasia, además de una oposición de objeciones pueriles y sin fundamento, trataron de desvirtuar y ridiculizar la asignatura, consiguiendo suprimirla del programa en la reforma de 1898 (García, 1908). A pesar de estos problemas, las mujeres que pasaban por esta escuela contribuirían claramente a la difusión de la gimnástica femenina, ya que tanto en sus destinos como en sus escritos, defendían la necesidad de la gimnasia para las niñas o las mujeres. Muchas de las que hoy consideramos primeras feministas españolas estuvieron de una forma $u$ otra vinculadas a estas instituciones.

En el caso de Barcelona, en la Escuela de Institutrices, la gimnasia también formó parte del programa de estudios a través de la materia "Gimnasia teórica y práctica". El matrimonio Emilia Colomer y Eduardo Tolosa fueron los encargados de dirigirla en las dependencias del Gimnasio que ambos poseían. Eduardo Tolosa era uno de los pocos profesores con título oficial de gimnástica de la ciudad. Fue costumbre de la escuela ofrecer exámenes públicos para mostrar y verificar los adelantos de las alumnas (Crónica Local, 1895), lo que contribuía a visibilizar la práctica de la gimnasia femenina.

Emilia Colomer de Tolosa, que en Barcelona se destacaba -según la prensa- como la profesora más acreditada en la enseñanza de la gimnástica, ejercía en la Escuela de Institutrices, en los colegios del Sagrado Corazón y Ntra. Sra. de Loreto, y en las Escuelas Municipales de Barcelona, así como en otros centros escolares de prestigio (Crónica Local, 1895). Este aspecto muestra cómo el profesorado dedicado a la educación física tenía, tanto si 
Torrebadella, X. y López-Villar, C. (2016). Las primeras profesoras de gimnástica en España. Profesión liberal y coartada durante el siglo XIX. RICYDE. Revista internacional de ciencias del deporte. 46(12), 423-442. http://dx.doi.org/10.5232/ricyde2016.04606

eran hombres como mujeres, que compaginar varios trabajos a la vez para poder vivir de esta profesión.

Al año siguiente del nacimiento de la Escuela de Institutrices en Barcelona, se crea en Madrid una plaza de profesora de gimnástica higiénica en la Escuela Modelo de Párvulos, vinculada a la Normal de Maestras. Fue ocupada por María de la Asunción Cosgaya, profesora oficial de gimnástica que también impartía clases para señoritas en la Sociedad Gimnastica Española (Noticias generales, 1893). Por la nombrada plaza pasarían distintas profesoras como Tomasa Palomo y Palomo (De Instrucción Pública, 1898) o Carmen Bayo (Noticias varias, 1899).

Aparecen así dos perfiles de profesoras: las maestras y las que procedían de familias con gimnasios, estas últimas combinaban su trabajo en los gimnasios familiares con clases en colegios privados y para "señoritas".

Con la creación de la Escuela Central de Gimnasia (ECG), se produce un salto cualitativo, ya que en su Reglamento se constató, de forma específica, la primera formación de mujeres como profesoras de educación física. Además, sus propuestas eran altamente innovadoras para la época, en oposición al artículo 10 del Reglamento, que preveía por separado las clases de gimnástica para los alumnos y las alumnas, la Escuela solicitó la impartición colectiva de la enseñanza. Como respuesta a dicha petición, la Inspección de la Administración realizó un dictamen favorable, trasmitiendo un claro apoyo a la formación de las mujeres para poder acceder a profesiones como la de profesora de gimnasia.

No participa esta Inspección de estas prevenciones; por el contrario considera muy conveniente favorecer toda tendencia encaminada a facilitar la existencia mixta en la mayor parte de los establecimientos públicos de instrucción como medio de impulsar la educación y la enseñanza de las mujeres y su acceso al ejercicio de profesiones para las que hoy están incapacitadas por no serle dable obtener los títulos académicos que según las leyes son necesarios[...] Será pues notablemente oportuno acceder a lo que propone la Escuela Central de Gimnástica[...] porque sirva de ejemplo y demostración práctica de que, lejos de estimarse perjudicial, se debe reconocer como ventajosa la educación común de alumnos y alumnas $\left[^{1}\right]$.

En cuanto a los contenidos, regían las mismas asignaturas para profesores y profesoras, si bien es cierto que las mujeres no realizaban esgrima y que las enseñanzas se acomodaban a lo que consideraban que más convenía al organismo de la mujer (Sección de noticias, 1890), aspecto que posiblemente estaría relacionado con la intensidad de los ejercicios y en línea con los discursos de la época.

De las ochenta plazas previstas, en el primer curso 87-88, treinta estaban destinadas para mujeres $^{2}$. Finalmente, después de la clausura de la ECG, dieciséis fueron las que alcanzaron el título de Profesoras de Gimnástica. Tal como figura en los archivos de la escuela, las profesoras oficiales de Gimnástica fueron Adela Borra García, Josefa Carmona Muntada, $\mathbf{M}^{\mathrm{a}}$. Asunción Cosgaya Rodríguez, Rafaela Cosgaya Rodríguez, Victoria Esteban Zorrilla, María Pilar Gil López, Encarnación de Granda Lahín, Jesusa de Granda Lahín, Josefa Mathet Crespo, Adelaida Muñoz García, Antonia Navarro Delgado, Encarnación Navarro Delgado, Encarnación Pérez Plaza, Ángela Serrano Gorostiza, Victoriana Serrano Ribero, Dativa Val

\footnotetext{
${ }^{1}$ Comunicaciones del Dtor. Gral. de Instrucción Pública, 30 de enero de 1887, AUCM, legado D-349.

${ }^{2}$ Comunicaciones del Sr. Rector, 20 julio de 1887, AUCM, legado D-349.
} 
Torrebadella, X. y López-Villar, C. (2016). Las primeras profesoras de gimnástica en España. Profesión liberal y coartada durante el siglo XIX. RICYDE. Revista internacional de ciencias del deporte. 46(12), 423-442. http://dx.doi.org/10.5232/ricyde2016.04606

Simón ${ }^{3}$. El perfil de estas mujeres era de maestras o tituladas en escuelas de institutrices (La Escuela Oficial de Gimnástica de Madrid, 1889).

Desde la creación de la ECG, Jesusa de Granda fue nombrada profesora para impartir nociones de "Pedagogía general". Se había titulado en la Escuela de Institutrices (Asociación para la enseñanza de la Mujer, 1884) y, como ayudante, se designó a la profesora María del Pilar Gil y López (Torrebadella, 2014b). Años más tarde, en concreto, en 1890, Encarnación Pérez accedió como profesora ayudante interina para las clases prácticas de "Juegos corporales" (Zorrilla, 2000). Esta profesora también se había titulado en la Escuela Central de Gimnástica en 1889 e impartía clases de gimnástica para señoritas en el Fomento de las Artes, una de las primeras entidades o asociaciones culturales privadas que organizaron clases de gimnástica femenina (Noticias, 1889).

Otro hecho a destacar es que las profesoras de la escuela también fueron premiadas por trabajos teóricos. Jesusa de Granda recibía en el año 1888 un premio por la obra Pedagogía gimnástica y María Pilar Gil López por dos obras Fisiología e higiene y Gimnástica con Aparatos (Cartera de Madrid, 1888). Este aspecto es de gran importancia, ya que se estaba valorando el conocimiento elaborado por mujeres.

La mayoría de las alumnas procedía de Madrid, pero también hubo casos como el de Josefina Carmona, cuñada del reputado profesor de gimnástica Salvador López Gómez. El centro de Salvador López, Gimnasio Médico de Sevilla, ofrecía "clases reservadas para señoritas" (Sanchís, 2010, 262). Este hecho, junto a las influencias que Salvador López hubiese podido recibir de sus viajes por el extranjero, nos hacen suponer que posiblemente tuviese interés en que las mujeres practicasen gimnasia y pudiese ocurrir, de modo que tampoco debería descartarse que la propia Josefina colaborase en su centro.

Otra profesora oficial de Gimnástica, fue Ángela Serrano Gorostiza, que en 1893 ejerció como primera vocal de la Junta Directiva de la Asociación Oficial de Profesores y Profesoras de Gimnástica (Noticias generales, 1893). También fue profesora durante varios años en el Fomento de las Artes, siendo propuesta en 1908, por el Dr. Eduardo Masip (1908), como maestra auxiliar de las escuelas municipales de gimnasia de Madrid.

En los inmediatos años después del cierre de la ECG, Jesusa de Granda tuvo una destacada actividad profesional, participando en congresos y publicando artículos de distinta índole (El Cansancio, 1897), además de impartir clases de gimnástica femenina en la Sociedad Gimnástica Española (Sección de noticias, 1893). A partir de la refundación de esta entidad en 1891, la presencia femenina fue en aumento, al contar en la Junta Directiva con dos vocales que eran Jesusa de Granda y María Magdalena Culebras (Sección de noticias, 1891). Dos años más tarde, Jesusa de Granda accedió a la vicepresidencia de la Sociedad Gimnastica Española con la colaboración de su compañera Dativa Val Simón, que ejerció como vocal (Gimnástica, 1893). La presencia de mujeres en la Junta directiva indica la voluntad del colectivo por incorporar el estímulo de las prácticas gimnástico-deportivas a la población femenina y de la actividad comprometida de estas mujeres. Incluso, Dativa Val había participado en la Comisión para redactar el reglamento de la Sociedad Gimnástica Española, constituida a principios de 1891 (Noticias generales, 1890; Reunión de Gimnastas, 1890). Años más tarde, concretamente en 1901, encontramos referencias a otra mujer que impartía

\footnotetext{
${ }^{3}$ Pueden consultarse los documentos acerca de la ECG en el Archivo Central del Ministerio de Cultura en Madrid. Ref. Escuela Central de Gimnástica, núm. 6085/6086.
} 
Torrebadella, X. y López-Villar, C. (2016). Las primeras profesoras de gimnástica en España. Profesión liberal y coartada durante el siglo XIX. RICYDE. Revista internacional de ciencias del deporte. 46(12), 423-442. http://dx.doi.org/10.5232/ricyde2016.04606

clases de gimnástica higiénica para señoritas en dicha Sociedad, que era Adela Borra (Sociedad Gimnástica Española, 1901).

De otras profesoras nos llegan noticias posteriormente, como el caso de Josefa Mathet Crespo, que aprobó oposiciones en 1897 para ejercer como maestra de una escuela elemental de niñas (Anuncios oficiales, 1897), o de Encarnación Navarro, como profesora de Educación Física de la Escuela Normal Central de Maestras, que participó en la Comisión Interministerial de Educación Física en 1927 (Ministerio de Guerra, 1927).

En 1892 encontramos anuncios en prensa de profesoras tituladas, que además ofrecen clases específicas para mujeres del siguiente tenor: "Señorita distinguida, profesora oficial de gimnasia que obtuvo en su carrera notas de sobresaliente y premios de honor, se ofrece para impartir lecciones de gimnasia higiénica a domicilio a señoras, señoritas y niños" (Gimnasia higiénica, 1892, 4).

O el del "Gimnasio Higiénico para Señoritas", en cuyo anuncio se explicaba que estaba dirigido por una profesora oficial de Gimnástica con premio de la Escuela Central suponemos que podría tratarse del gimnasio de Encarnación Pérez-, bajo la inspección de un doctor de medicina (Gimnasio Higiénico para Señoritas, 1892). Dado que las mujeres a finales del siglo XIX eran, en muchos casos, educadas en sus hogares, el hecho de realizar lecciones de gimnasia a domicilio podría facilitar que algunas familias accediesen a que las chicas o niñas realizasen ejercicios higiénicos, por tratarse de un espacio seguro e íntimo.

Independientemente del género, los profesores de gimnasia que se formaron en la ECG defendieron a lo largo de su carrera la práctica de la gimnasia por las mujeres. Los profesores también abrían establecimientos, ofreciendo clases para mujeres. Así pues, parece que la posibilidad que tuvieron como alumnos y alumnas de compartir clases comunes fue un elemento muy positivo para valorar la educación física femenina.

Tal como vimos al inicio de este apartado, será en los gimnasios donde primero ejerzan las mujeres esta profesión. Tras las primeras profesoras, ya nombradas, hay que destacar a Cristina Amigo, que en 1880 figuraba como directora junto a su marido Joaquín Ramis del Gimnasio Español. Entre 1881 y 1894, doña Elisa Ros, esposa de Francisco Solé, se encargaba de las clases de gimnasia para señoras en el Gimnasio que llevaba el nombre de su marido.

Adjunt al gimnás d' homes n' hi há un altra d' independent per senyoras, dirigit per donya Elisa Ros, l'esposa del senyor Solé, que rivalisa ab ell en inteligencia per robustir las forsas d'un sexo á qual debilitat tant contribuhexen las sedentarias ocupacions de las clases no populars. Per facilitar aquest objecte, la senyora de Solé aten á sas dexeblas á totas las horas laborables, ab una amabilital exemplar, inclusas las de la nit ${ }^{4}$. (García del Real, 1886, 174)

En el año 1882, encontramos en anuncios insertados en El Gimnasta Español la figura de Joana Sampérez, que impartió clases para mujeres en el Gimnasio de Luciano Sampérez de Badajoz. Lo mismo hizo Doña Gabina Enríquez en el Gimnasio Médico de Eugenio Fernández en Zaragoza, o Carolina Yárritu en el Gimnasio de Emilio Castañón, en Madrid. En ese mismo año se contabilizaban la nómina de cuarenta y nueve profesionales de la

\footnotetext{
4 "Al lado del gimnasio de hombres hay otro independiente para señoras, dirigido por doña Elisa Ros, esposa del señor Solé, que rivaliza con él en inteligencia para fortalecer las fuerzas de un sexo a cuya debilidad tanto contribuyen las ocupaciones sedentarias de las clases no populares. Para facilitar este objetivo, la señora Solé atiende a sus discípulas a todas las horas laborables, con una amabilidad ejemplar, incluidas las de la noche".
} 
Torrebadella, X. y López-Villar, C. (2016). Las primeras profesoras de gimnástica en España. Profesión liberal y coartada durante el siglo XIX. RICYDE. Revista internacional de ciencias del deporte. 46(12), 423-442. http://dx.doi.org/10.5232/ricyde2016.04606

gimnástica en España, cuarenta y seis hombres y tres mujeres, son las que acabamos de citar (Hespanha, 1882). Años más tarde, en Barcelona, el Gran Gimnasio Higiénico, Ortopédico y Recreativo para ambos sexos, de Fidel Bricall, recibía la ayuda de su hija Teresita, que impartía clases especiales para señoras (Gran Gimnasio Higiénico, 1889). El número total de mujeres implicadas en el ámbito de la gimnasia es difícil de determinar, ya que muchas veces ejercían dentro de los negocios familiares.

En Badajoz, hacia 1890, Pilar Sampérez, que era hija del gimnasiarca Luciano Sampérez, también trabajaba como profesora de señoritas en el gimnasio de su padre. Había participado desde pequeña en exhibiciones gimnásticas, ejecutando ejercicios sobre el trapecio, siendo por ello descrita como "notable equilibrista". Llegó a realizar exhibiciones en Portugal y otras veces en trapecio doble, en compañía de María Cabezas. En 1897, abrió con la titulación de maestra de primera enseñanza un Colegio de niñas, en el que la educación física fue un elemento de especial consideración. Combinaba el trabajo en el gimnasio de la familia y en el centro escolar. En el mismo gimnasio también aparece Luisa Ladrón de Guevara como encargada del tratamiento hidroterápico para señoras y Luisa Sampérez como profesora. En fin, Pilar ejercería a partir de 1910 como titular de partos, según aparece en los anuncios del gimnasio de su padre, llegando a presidir del colegio de matronas (Rebollo, 2009).

Entre los años 1863 y 1872, los gimnasios que atendieron clases para mujeres fueron los de Joaquín Ramis, hermanos Vall y Florencio Quadras. En el caso de los hermanos Vall, María Vall era la encargada de las clases de señoras y señoritas en el Gran Gimnasio Europeo, Higiénico y Ortopédico (Dalmau, 1947).

A partir de 1890, prácticamente todos los gimnasios llamados higiénicos disponían de alguna profesional de la familia, de modo que el acceso a este ámbito era, en la mayoría de los casos, por vinculaciones familiares. A las esposas nombradas a lo largo del artículo podemos añadir a Delfina Domingo en el Gimnasio Modelo de Andrés Arias.

En el "Gimnasio Modelo" de nuestro amigo don Andrés Arias, instalado en los bajos de la calle Cervantes, núm. 2, se están efectuando importantes reformas y en breve quedará inaugurado un nuevo salón de gimnasia destinado exclusivamente para señoras y señoritas, con todos los adelantos que la ciencia requiere, estableciéndose dos secciones, una de trabajo y otra de recreo, bajo la dirección de doña Delfina Domingo de Arias, y con la cooperación de profesoras auxiliares competentes. (Gimnástica, 1899, 847-848)

Esta profesora se presentaba cinco años más tarde como profesora de masaje, encargada de dicha sección y de las clases para señoras y señoritas (Gimnasia, 1904). Del mismo modo, en Tarragona, en el gimnasio de Tomás Martí, este profesor estaba acompañado por su hija (Gran Gimnasio, 1896).

Los discursos morales sobre la necesidad de que las mujeres asistiesen a clases dirigidas por mujeres, junto a las ideas progresistas de que la mujer pudiese acceder a ciertas profesiones, potenciarían la necesidad de que en los gimnasios se incluyese entre su personal a profesoras.

En cuanto a las características de la práctica, podemos decir que en los gimnasios decimonónicos la gimnasia para "ambos sexos" siempre fue en espacios y/o en horarios separados, por lo que la forma mixta en la que se impartió en la Escuela Central de Gimnasia fue una propuesta muy avanzada para su momento.

\section{El complicado ejercicio de la profesión de profesora de gimnasia}

Respecto a la profesión de profesora de gimnasia, hay que tener en cuenta el momento social en el que se produce. Las mujeres estaban intentando abrirse camino en el ámbito laboral con 
Torrebadella, X. y López-Villar, C. (2016). Las primeras profesoras de gimnástica en España. Profesión liberal y coartada durante el siglo XIX. RICYDE. Revista internacional de ciencias del deporte. 46(12), 423-442. http://dx.doi.org/10.5232/ricyde2016.04606

muchas dificultades. A las mujeres de diferentes clases sociales se les ponían trabas, no se veía bien que ocupasen los espacios tradicionales de los hombres, ni que trabajasen en fábricas, además se les ponían barreras para acudir a la universidad y formarse. En el caso de la educación física, existían problemas entre el estatus del profesorado de esta especialidad con respecto a otras asignaturas, ya que se cobraba menos, lo que provocaba la necesidad de pluriemplearse. En el caso de las mujeres, como analizaremos en este apartado, la problemática era mayor.

La poca presencia de mujeres ejerciendo de profesoras en centros oficiales estaba provocada por la falta de convocatoria de cátedras en institutos y escuelas normales, tal como denunciaba el Dr. Fraguas $(1899,131)$, pues eran -según sus propias palabras- "ilegalmente postergadas". Así pues, aunque un grupo de mujeres habían accedido a formarse para ejercer como profesoras de gimnasia, la realidad laboral las vetaba. Hecho que también denunciaban las propias mujeres. Paula Trapero, natural de Burgos, que se tituló en 1900 como profesora (Miscelánea, 1900), criticaba el nivel de la gimnástica femenina en los institutos, aun siendo estudiante, y reclamaba la necesidad de que se permitiera a las profesoras impartirla.

El estudio de la gimnasia higiénica ocupa en la esfera del saber humano un rango más positivo y superior que el que hoy se le quiere dar, suponiendo algunos que no son más que saltos y volatines; y para convencerse de ello no hay más que echar una mirada hacia el Decreto que la instituyó como obligatoria en los Institutos y el resultado que de seguro ha de dar, una vez implantada en las Escuelas Normales Superiores de maestras, y cuando estas profesoras puedan transmitirla a sus alumnas; entonces veremos desaparecer, de seguro, esas niñas raquíticas, enclenques y cloroanémicas, primeros pasos de esas tisis generalizadas que tantas víctimas tiene a su costa la sociedad pequeña. (Trapero, 1899, 133-134)

Incluso con el cambio de siglo, el profesor Adolfo Revuelta, entonces presidente de la Asociación de Profesores y Profesoras Oficiales de Gimnástica, seguía denunciando la poca atención a las profesoras de gimnástica:

En este caso creímos también oportuno poner bajo el amparo de la Infanta D. Isabel los derechos de nuestras compañeras las profesoras de gimnástica, cuyos títulos no han sido tenidos para nada en cuenta al hacerse la última reforma de estudios y prácticas en las Normales de Maestras, y hora es ya, de que tan dignas y olvidadas compañeras sean reintegradas en sus derechos, y que la educación física de la mujer, por la cual todo el mundo aboga en teoría, sea atendida en aquellos centros con toda la extensión y garantías que su cultura corporal exige. (Revuelta, 1902, 463)

Pero lejos de solucionarse, estas denuncias continuarían durante años, Alcántara García (1908) se quejaba que, tras cerrarse la Escuela Central de Gimnástica y pese a haberse formado en ella profesoras oficiales de Gimnástica, ninguna de ellas fue acreditada para impartir la asignatura en la Escuela Normal Central de Maestras.

A esta falta de atención por parte de las autoridades para convocar cátedras que pudiesen ocupar profesoras, había que sumar las polémicas en torno al intrusismo. Como ejemplo de ello está el caso que ocurrió en 1896, cuando Milagros Morales fue cesada del cargo de profesora de Gimnastica de la Escuela de Jardines de Infancia, tras diez años de servicios, y se colocó como substituta a Doña María Azuaga, que no poseía título oficial de profesora de Gimnástica. Este atropello en la profesión fue denunciado a la prensa en diferentes ocasiones (Cosas de la enseñanza, 1896). 
Torrebadella, X. y López-Villar, C. (2016). Las primeras profesoras de gimnástica en España. Profesión liberal y coartada durante el siglo XIX. RICYDE. Revista internacional de ciencias del deporte. 46(12), 423-442. http://dx.doi.org/10.5232/ricyde2016.04606

Como puede apreciarse, a las profesoras no les quedaba más remedio que ejercer como profesoras de gimnasia desde su oficio de maestras o desde la práctica privada en gimnasios. No existía una voluntad política que les permitiese ser profesoras de educación física en niveles superiores.

\section{Los discursos de las propias mujeres}

Como hemos comentado anteriormente, en el Congreso Pedagógico de 1892, las mujeres toman la palabra para demandar la educación física. Siendo profesora de la Escuela Central de Gimnasia, Jesusa de Granda reclamaba el derecho y la necesidad de atender la educación física de las mujeres a partir del ejercicio de la profesión gimnástica femenina, reivindicación que plasmará en sus escritos.

La mujer, más que el hombre, necesita una dirección en el ejercicio que ha de desenvolver y educar su cuerpo. En primer lugar, por su alta misión de madre en la naturaleza; en segundo, porque su ser debilitado por la falta de educación anterior, necesita cuidados especiales para recompensar pérdidas sufridas durante siglos enteros de ignorante rutina y ciego fanatismo.

$[\ldots]$

En nuestro concepto, la mujer como el hombre, debe comenzar por su educación física, por el desarrollo de su cuerpo, que como templo del alma, que dice san Agustín, ha de ser digno alcázar de tan divino huésped. [...]

Por esto la gimnástica femenina no ha de exigir grandes esfuerzos musculares, sino regulares movimientos de su organismo. No debe asemejarse a la gimnástica masculina, porque en ambas el fin es diferente. La gimnástica femenina debe estar dirigida por la mujer misma y no por el hombre.

De aquí la importancia de la misión de la profesora de gimnástica. Ella viene a llenar en nuestra sociedad un vacío que nadie pudo cumplir. Ella viene a redimir su sexo de las cadenas que más miserable la hacen, de aquellas que la constituyen esclava de su cuerpo anémico y raquítico. (Granda, 1983a, 123-124)

Granda (1897) entendía el ejercicio físico de las mujeres en el sentido de prepararlas para sus funciones sociales y permitir a través del desarrollo físico, el desarrollo del alma. Para ella el ejercicio era un deber humano y consideraba como sociedad insensata y miserable la sociedad que negaba la educación a la mujer, ensalzando, al mismo tiempo, el modelo de mujer que preservaba la estructura familiar (Granda, 1894).

De aquí que la mujer, no solo por sí, sino por su familia necesita una educación adecuada, una preparación indispensable. Nadie en tan alto grado como ella necesita, para la lucha constante de la vida, un cuerpo robusto que resista las penalidades que la naturaleza le reserva, un sentimiento delicado en su misión de educadora, una inteligencia clara para juzgar y dirigir al educando, una voluntad firme y enérgica dispuesta á luchar con los deseos de los demás al par que con los suyos propios, una personalidad entera, en una palabra.

Observando y reflexionando sobre el tema que nos ocupa, fácil es distinguir que el bien y el mal que la mujer determina es más real, más profundo y decisivo para la humanidad que el llevado á cabo por el hombre, y que ella es, en la sociedad en que vive, ángel redentor que ha de salvarla ó Luzbel que ha de empequeñecerla y aniquilarla. 
Torrebadella, X. y López-Villar, C. (2016). Las primeras profesoras de gimnástica en España. Profesión liberal y coartada durante el siglo XIX. RICYDE. Revista internacional de ciencias del deporte. 46(12), 423-442. http://dx.doi.org/10.5232/ricyde2016.04606

Al educar la sociedad á la mujer recogerá centuplicados sus beneficios, pues como ya dijo un célebre pensador: educar á una niña es “educar á la sociedad”. (Granda, 1898, 113)

En este caso, se observa claramente que esta profesora sitúa a las mujeres en un nivel superior de moralidad frente a los hombres. Puede incluirse, por ello, en el denominado feminismo social, ya que, aunque defendía la educación de la mujer y su educación física, no trasciende su rol tradicional de esposa y madre.

Pero a pesar de que algunas mujeres alzaban sus voces con contundencia, detectamos rápidamente la misoginia de la época, en el caso de los escritos que recibe Paula Trapero Calleja, primera mujer en superar la prueba de reválida como Profesora de Gimnástica en 1900 , en respuesta a sus opiniones sobre la gimnasia. Ante una crítica que realiza a la situación de la profesión y de la materia, recibe réplica de dos profesores, que es la siguiente:

El profesorado de gimnasia, sin duda se lisonjera con el advenimiento y cooperación del bello sexo en una obra que es realmente de interés general; y siendo el elemento de educación, es indudablemente que en él puede hacer mucho la mujer.

Pero es opinión muy extendida que las mujeres son superficiales y hablan, y hablan de lo que no entienden: por esta razón desearíamos que se fijaran bastante en lo que traten respecto de esta materia de enseñanza, y digan lo que sepan y entiendan, pero no con seguridad en lo que expongan, sea mucho o poco lo que aporten al juicio de las gentes. (La enseñanza de la gimnasia en los Institutos, 1899, 125-126)

En este texto se observa, claramente, la referencia a su condición de mujer para despreciar, en general, a las mujeres. Esto no evita que Paula se defendiese y volviese a exponer sus ideas, intentando hacer entender al catedrático Pedro Castellanos que había interpretado mal sus palabras:

Al recibir una maliciosa cual satírica felicitación por nuestra valentía al meternos á escribir para la prensa un modesto y humilde artículo profesional, por pertenecer á la honrosa clase de profesoras de Gimnasia higiénica, debemos hacer público, y con especialidad al autor de la citada carta, que no ha sido la osadía la que nos ha impulsado á hacerlo, sino el deseo de expresar nuestro modo de pensar respecto á la humilde, aunque honrosísima, clase de profesores y profesoras de esta enseñanza especial, hoy casi naciente, y cuyos beneficiosos resultados no se han de ver con claridad hasta que el desenvolvimiento orgánico y el desarrollo físico de la sociedad naciente nos demuestre palpablemente las víctimas que arranca de las garras de la muerte. No ha sido tampoco nuestro ánimo el deseo de exhibición, no, señor profesor incógnito; lo que pretendemos es llamar la atención del Profesorado y de los Gobiernos para que se armonice esta enseñanza, se la dé forma y se la dé vida, elevándola, por ser muy necesaria, á la categoría de disciplina utilizable por sus provechosos conocimientos y utilidad incuestionable, arrancándola del estado pasivo en que hoy se enseña en los Institutos, sometida á una serie de juegos juveniles, provechosos, sí, pero organizados de tal suerte, que no son susceptibles de poderse exponer ante un examen de tribunal de profesores por no estar sujetos á programa, orden ni concierto. (Trapero, 1889, 133). 
Torrebadella, X. y López-Villar, C. (2016). Las primeras profesoras de gimnástica en España. Profesión liberal y coartada durante el siglo XIX. RICYDE. Revista internacional de ciencias del deporte. 46(12), 423-442. http://dx.doi.org/10.5232/ricyde2016.04606

\section{Conclusiones}

De este modo, la profesión de profesora de gimnasia nació vinculada a un ámbito familiar y dentro de los gimnasios, para posteriormente avanzar tímidamente hacia una formación reglada en la Escuela Central de Gimnasia, que fracasará debido a la falta de cátedras en los institutos de segunda enseñanza, que pudiesen ocupar mujeres.

Será la profesión de maestra y los gimnasios familiares los que permitirán el ejercicio de la profesión, que facilitarán incluso la independencia de algunas mujeres al crear clases particulares o sus propios negocios. Las mujeres han de desarrollar múltiples estrategias para poder trabajar y desarrollarse, observándose un apoyo importante entre ellas en diferentes situaciones. Unas desde los discursos y otras desde la acción, reivindicarán el acceso a la educación, la salud y nuevas profesiones.

Un caso significativo de los que hemos estudiado es el de Teresa Castellanos, ya que se puede considerar una pionera desde diferentes puntos de vista. Teresa introduce una nueva corriente gimnástica, la de los ejercicios calisténicos femeninos de Clias, realiza una práctica como la esgrima, poco habitual en mujeres, por sus connotaciones bélicas, imparte clases tanto a hombres como mujeres y regenta su propio negocio gimnástico.

A diferencia con lo que ocurrió en otros países, la falta de apoyo a iniciativas educativas fuertes de educación de las mujeres, no permitió un desarrollo proporcionado de la función docente en educación física, hecho que sí ocurrió en lugares como Reino Unido o Estados Unidos, en donde la profesión de profesora de gimnasia era una oportunidad de empleabilidad en la importante red de colegios y escuelas de educación exclusiva para mujeres.

Aunque es necesario destacar la importante influencia de la ideología krausista y de la Institución Libre de Enseñanza -que a través de sus iniciativas apoyaban la profesionalización de las mujeres-, la fuerte moral católica dificultaba la aparición de nuevos espacios para las mujeres. A esto hay que sumar que el movimiento feminista, del momento, en España era incipiente y se encontraba con grandes resistencias.

\section{Referencias}

\section{A.V. (1882, 1 de agosto). El Gimnasta Español, 7, 1-2.}

Anuncios (1821, 1 de marzo). Diario de Barcelona, 535.

Anuncios oficiales (1897, 30 de marzo). La Gaceta de Instrucción Pública, 802-803.

Arada, R. de la (2005). L'educació al segle XIX: teoría de les esferes i els models de professionalització. Educació i història, 8, 147-163.

Arbaiza, M. (2000). La "cuestión social" como cuestión de género. Feminidad y trabajo en España (1860-1930). Historia Contemporánea, 21, 395-458.

Arbaiza, M. (2002). La construcción social del empleo femenino en España (1850-1935). Arenal: Revista de historia de mujeres, 9(2), 215-239.

Arellano, M. (1894). Educación física. Gimnástica higiénica - médica y ortopédica. Castellón: Tomas Boix.

Asociación para la enseñanza de la Mujer (1884, 8 de diciembre). El Liberal, 1.

Ballarín, P. (1999). Maestras, innovación y cambios. Arenal, 6(1), 81-110.

Ballarín, P. (2007). La escuela de niñas en el siglo XIX: la legitimación de la sociedad de esferas separadas. Historia de la educación, 26, 143-168. 
Torrebadella, X. y López-Villar, C. (2016). Las primeras profesoras de gimnástica en España. Profesión liberal y coartada durante el siglo XIX. RICYDE. Revista internacional de ciencias del deporte. 46(12), 423-442. http://dx.doi.org/10.5232/ricyde2016.04606

Ballarín, P. (2011). Nuestras predecesoras en el magisterio: una mirada al pasado para construir el futuro. En V. Marín y M. R. Fortes (coord.), I Jornadas sobre igualdad y género (pp. 11-32). Ceuta: Universidad de Granada, Facultad de Educación y Humanidades de Ceuta.

Busqué, S. (1865). Gimnástica higiénica, médica y ortopédica o el ejercicio considerado como medio terapéutico. Madrid: Imp. Manuel Galiano.

Carbajosa, C. (1999). Las profesoras de Educación Física en España: Historia de su formación (1938-1977). Oviedo: Servicio de Publicaciones de la Universidad de Oviedo.

Cartera de Madrid (1888, 23 de junio). El Liberal, 4.

Círculo Gimnástico Barcelonés (1871, 9 de enero). La Convicción, 171.

Cortada, E. (1999). De la 'calcetera' a la maestra de escuela: expectativas y activismo profesional. Arenal, 6(1) 31-53.

Cortada, E. (2000). El acceso de las maestras al magisterio público en el siglo XIX: ¿Concesión o logro profesional?. Historia Social, 38, 35-55.

Cosas de la enseñanza (1896, 29 de febrero). El País, 2.

Crónica local (1894, 30 de septiembre). La Dinastía, 2-3.

Crónica local (1895, 18 de junio). La Dinástica, 2.

Dalmau, A. R. (1847). El circo en la vida barcelonesa. Crónica anecdótica de cien años circenses. Barcelona: Ediciones Librería Milla.

De Instrucción Pública (1898, 12 de julio). El Día, 2.

El Cansancio (1897, 25 de octubre). El Globo, 3.

Escuelas Especiales (1900, 23 de julio). Gaceta de Instrucción Pública, 585.

Fernández-Quintanilla, P. (1981). La mujer ilustrada en la España del siglo XVIII. Madrid: Ministerio de Cultura.

Ferrer, E. (1882, 15 de diciembre). Necesidad de la gimnasia para las mujeres. El Gimnasta Español, 5-6.

Flecha, C. (1996). Las primeras universitarias en España: 1872-1910. Madrid: Narcea ediciones.

Flecha, C. (2007). Lo que piensan las mujeres acerca de su educación. Historia de la Educación, 26, 395-435.

Fraguas, J. E. (1899, 15 de abril). Por la gimnástica oficial y su dignificación", Los Deportes, 130-131.

García del Real, L. (1886, 15 de marzo). Notas d'industria, d'gimnasia i d'higiene. La Ilustració Catalana, 174.

García-Fraguas, J. E. (1896). Tratado racional de gimnástica y de los ejercicios y juegos corporales..., t. III. Madrid: Imp. Viuda. de Hernando y Cia.

García, P. A. de (1908). Teoría y práctica de la educación y la enseñanza, t. V. Madrid: Lib. de Sucesores de Hernando.

Gimnasia (1879, 13 de abril). Revista Universal Ilustrada, 2-3.

Gimnasia higiénica (1892, 16 de febrero). La Época, 4.

Gimnasia (Barcelona, 1904, 29 de octubre). Los Deportes, 684-685. 
Torrebadella, X. y López-Villar, C. (2016). Las primeras profesoras de gimnástica en España. Profesión liberal y coartada durante el siglo XIX. RICYDE. Revista internacional de ciencias del deporte. 46(12), 423-442. http://dx.doi.org/10.5232/ricyde2016.04606

Gimnasio Higiénico para Señoritas (1892, 10 de marzo). La Correspondencia de España, 4.

Gimnasio Médico de Eduardo Tolosa (Barcelona, 1897). Folleto publicitario.

Gimnástica (1893, marzo). Crónica del Sport, 26.

Gimnástica (1899, 3 de septiembre). Los Deportes, 847-848.

González-Serrano, U. (1899). El feminismo. La Escuela Moderna, 98, 321-329.

Gran Gimnasio (1872, 13 de marzo). La Convicción, 807.

Gran gimnasio (1896, 3 de noviembre). Diario de Tarragona, 4.

Gran Gimnasio Higiénico (1889, 15 de septiembre). La Vanguardia, 4.

Gran gimnasio (Tarragona, 1896, 3 de noviembre). Diario de Tarragona, 4.

Granda, J. de (1893a, 16 de abril). Gimnástica femenina. Crónica del Sport, 123-124.

Granda, J. de (1893b, 16 de junio). Gimnástica. Crónica del Sport, 180-181.

Granda, J. de (1893c). Excursiones por el campo. La Escuela Moderna, 28, 22-25.

Granda, J. de (1894, 12 de febrero). La carrera. La Iberia, 2.

Granda, J. de (1897, 30 de agosto). Excursión. El Álbum ibero americano, 377.

Granda, J. de (1898, 14 de marzo). Educación de la mujer. El Álbum Ibero americano, 113.

Hespanha (1883, 30 de noviembre). O Gymnasta, 8.

La enseñanza de la gimnasia en los Institutos (1899, 15 de abril). Los Deportes, 125126.

La Escuela Oficial de Gimnástica de Madrid (Madrid, 1889, 15 de marzo). La Ilustración española y americana, 163.

Lladó, J. (1868). Nociones de gimnástica higiénica, aplicables a las escuelas de instrucción primaria de uno y otro sexo como elementos de educación física. Barcelona: Lib. de Juan Bastinos e Hijo.

López, S. (1882, 15 de diciembre). La gimnástica en el bello sexo. El Gimnasta Español, $12,3-4$.

Manrique, J. C. (2010). Las profesoras de Educación Física en la Sección Femenina Segoviana. Investigación histórica del ideal de mujer. Buenos Aires: Miño \& Dávila.

Masip, E. (1908). Consideraciones acerca de la gimnástica escolar. La Escuela Moderna, $30(206), 753-761$.

Ministerio de Guerra (1927, 1 de abril). Diario Oficial Ministerio de la Guerra, 3.

Miscelánea (Barcelona, 1900, 12 de agosto). Los Deportes, 509.

Moreno-Martínez, P. L., y Viñao-Frago, A. (2000). Higienismo y educación (siglos XVIII$\mathrm{XX}$ ). Áreas [en línea]. 20, Introducción. Disponible en:

http://revistas.um.es/areas/article/viewFile/144621/129561 [marzo de 2015]

Mosso, Á. (1894). La educación física de la juventud, seguida de La educación física de la mujer. Madrid: Librería de José Jorro.

Nash, M. (1983). Mujer, familia y trabajo en España (1875-1936). Barcelona: Anthropos.

Nash, M. (1995). Identitat cultural de gènere, discurs de la domesticitat i definició del treball de les dones a I'Espanya del segle XIX. Documents d'anàlisi geográfica, 26, 135-146. 
Torrebadella, X. y López-Villar, C. (2016). Las primeras profesoras de gimnástica en España. Profesión liberal y coartada durante el siglo XIX. RICYDE. Revista internacional de ciencias del deporte. 46(12), 423-442. http://dx.doi.org/10.5232/ricyde2016.04606

Noticias (1889, 27 de septiembre). La Iberia, 3.

Noticias (1893, 8 de julio). La Iberia, 2-3.

Noticias (1896, 5 de septiembre). Gaceta de Instrucción Pública, 1143.

Noticias generales (1890, 30 de noviembre). La Época, 3.

Noticias generales (1893, 11 de septiembre). La Época, 3.

Noticias varias (1899, 7 de julio). El Día, 2.

Orriols, J. B. (1895). Discurso como director-Presidente de la Escuela de Institutrices y otras carreras para la mujer inaugurando la fiesta de la ilustración femenina celebrada en el gran salón del Palacio de Bellas Artes el día 28 de abril de 1895. Barcelona: Imp. Subirana Hermanos..

Pajarón, R. (2000). La educación física escolar en España en la primera mitad del siglo $X X$. Departamento de Teoría e Historia de la Educación, Facultad de Educación, Universidad Complutense de Madrid. [Tesis doctoral no publicada].

Panadés, J. (1877). La educación de la mujer según los más ilustres moralistas e higienistas de ambos sexos -t. I.-. Barcelona: Jaime Seix y Compañía.

Parada (1882, 1 de enero). A las mujeres. La gimnasia. El Gimnasio, 4-5.

Pascual, P., y Viñas, J. (1896). La educación de la mujer. Tratado pedagógico para las maestras de primera enseñanza. Barcelona: Editor y Librería de Antonio J. Bastinos.

Rebollo, A. (2009). Notas para la historia del Gran Gimnasio de Badajoz (1868-1936). Revista de Estudios Extremeños, 55(2), 865-932.

Reunión de gimnastas (1890, 2 de diciembre). La República, 3.

Revista de los gimnasios (1882a, 1 de diciembre). El Gimnasta Español, 3-4.

Revista de los gimnasios (1882b, 1 de junio). El Gimnasta Español, 3-4.

Revuelta, A. (1902, 3 de agosto). Asamblea del Profesorado Oficial de Gimnástica. Los Deportes, 463-464.

Riquelme, A. (1885). Nociones de higiene doméstica escritas para la enseñanza en las escuelas normales y primarias. Madrid: Librería de Hernando.

Sánchez, J. (1884). Propaganda Gimnástica. Madrid: Imp. de Minuesa de los Ríos.

Sanchís, J. P. (2010). La actividad gimnástica y deportiva en Sevilla durante el siglo XIX. Sevilla: Diputación de Sevilla.

Sardá, A. (1882, 1 de octubre). La gimnasia. Instrucción para la mujer, 225-227.

Scanlon, G. (1986). La polémica feminista en la España contemporánea, 1868-1974. Madrid: Akal.

Sección de noticias (1890, 2 de junio). El Imparcial, 1-2.

Sección de noticias (1891, 3 de febrero). El Imparcial, 3.

Sección de noticias (1893, 15 de septiembre). El Imparcial, 3.

Sección oficial (1882, 16 de agosto). Instrucción para la mujer, 193-192.

Seraine, L. (1876). Higiene física y moral de los niños (4a ed.). Madrid: Imp. Médica de Álvarez Hermanos.

Simón, M. del C. (1972). La enseñanza privada seglar de grado medio en Madrid (18201868). Madrid: Instituto de Estudios Madrileños.

Sociedad Gimnástica Española (1894, 3 de junio). La Correspondencia de España, 4. 
Torrebadella, X. y López-Villar, C. (2016). Las primeras profesoras de gimnástica en España. Profesión liberal y coartada durante el siglo XIX. RICYDE. Revista internacional de ciencias del deporte. 46(12), 423-442. http://dx.doi.org/10.5232/ricyde2016.04606

Sociedad Gimnástica Española (1901, 31 de mazo). El País, 4.

Suárez, C. (Ed.) (2009). Maternidades. (De)construcciones feministas. Oviedo: KRK.

Tacoronte, M. J. (2012). Entre avance y conservación: mujer, ciencia y españolismo. En Memorias del IX Congreso Iberoamericano de Ciencia, Tecnología y Género, [en línea], Comunidad de Madrid, Organización de Estados Iberoamericanos, 2012. Disponible en: http://www.oei.es/congresoctg/memoria/mesas.php [febrero de 2015]

Torrebadella, X. (2011a). La educación física y la actividad gimnástico-deportiva de las mujeres a partir de la bibliografía especializada del siglo XIX. Arenal, 18(1), 147-179.

Torrebadella, X. (2011b). Repertorio bibliográfico inédito de la educación física y el deporte en España (1800-1939). Madrid: Fundación Universitaria Española.

Torrebadella, X. (2013a). Del espectáculo acrobático a los primeros gimnasios modernos. Una historia de las compañías gimnástico acrobáticas en la primera mitad del siglo XIX en España. Aloma, 31(2), 67-84.

Torrebadella, X. (2013b). La educación física femenina en el período Isabelino (18331868): Teresa Castellanos de Mesa, primera profesora española de gimnástica. Àgora para la educación física, 15(1), 20-39.

Torrebadella, X. (2014a). La influencia de la profesión médica en la educación física española del siglo XIX: Análisis social del Manual popular de gimnasia de sala, médica e higiénica del Dr. Schreber. Cultura, Ciencia y Deporte, 9(26), 163-176. http://dx.doi.org/10.12800/ccd.v9i26.434

Torrebadella, X. (2014b). Los apóstoles de la educación física. Trece semblanzas profesionales en la educación física española contemporánea. Revista Española de Educación Física, 406, 57-76.

Torres-Campos, R. (1884). La reforma en la enseñanza de la mujer y la reorganización de la Escuela Normal Central de Maestras. Madrid: Est. Tip. de El Correo a cargo de F. Fernández.

Trapero, P. (1899, 15 de mayo). Al César lo que es del César. Gaceta de Instrucción Pública, 133-134.

Varela, J. (1983). Modos de educación en la España de la Contrarreforma. Madrid: Ed. La Piqueta.

Varela, J. (1997). Nacimiento de la mujer burguesa: el cambiante desequilibrio de poder entre los sexos. Madrid: La Piqueta.

Zagalaz, M. L. (2001). La educación física femenina durante el franquismo. La Sección Femenina. Apunts. Educación Física y Deportes, 65, 6-16.

Zorrila, P. P. (2000). La Escuela Central de Profesores y Profesoras de Gimnástica. En Nacimiento e implantación de la educación física en España: Los tiempos modernos (pp. 61-111). Madrid: Consejo Superior de Deportes. 